\title{
The Relationship Between Social Intelligence and Academic Achievement in Anesthesiology and Operating Room Students of Tehran University of Medical Sciences
}

Mohammadi. A 1
Mojtahedzadeh. R2
*Shamsi. A ${ }^{3}$
1- MD, Assistant Professor,
Department of E-learning in
Medical Education, Faculty of
Virtual, Tehran University of
Medical, Tehran, Iran.
2- MD, Assistant Professor,
Department of E-learning in
Medical Education, Faculty of
Virtual, Tehran University of
Medical, Tehran, Iran.
3- ('Corresponding author)
Assistant Professor,
Anesthetics Group, School
of Allied Medicine, Tehran
University of Medical Sciences,
Tehran, Iran. Nursing and
Midwifery Care Research
Center, Tehran University of
Medical Sciences, Tehran,
Iran. Email: afzal_sh63@
yahoo.com

\begin{abstract}
Introduction: Students' academic achievement is one of the important parameters in higher education system. By timely identification of students at risk of dropping out and taking the necessary measures, their academic status can be improved. Social intelligence can greatly predict students' academic achievement.
\end{abstract}

Objective: The current study aimed at determining the relationship between social intelligence and academic achievement in anesthesiology and operating room students of Tehran University of Medical Sciences.

Materials and Methods: The current cross sectional study was conducted on anesthesiology and operating room students of Tehran University of Medical Sciences in 2018. A total of 140 subjects were selected by convenience sampling method. Demographic questionnaire and the Bradbury and Tromso standard questionnaire for social intelligence were employed as data collection instruments. To measure academic achievement, the overall GPA of the students was used. Data were analyzed using SPSS software version 24 and $\mathrm{P}<0.05$ was considered as the level of significance.

Results: The mean age of students was $20.54 \pm 1.33$ years. Mean score of social intelligence was higher in male students than female ones ( $4.75 \pm 0.85$ vs. $4.65 \pm 0.77)$ $(\mathrm{T}=0.743, \mathrm{df}=138, \mathrm{P}=0.459)$. Pearson correlation coefficient showed a positive and significant correlation between academic achievement and social intelligence $(\mathrm{r}=0.613)$ and all its dimensions ( $\mathrm{i}$ e, social information processing $(\mathrm{r}=0.581)$, social skills $(\mathrm{r}=0.445)$, and social awareness $(\mathrm{r}=0.481)(\mathrm{P}=0.000)$.

Discussion and Conclusion: The mean score of students' social intelligence and its dimensions was in the desired level. There was a positive and significant relationship between social intelligence and all its dimensions with academic achievement. Therefore, it is suggested to plan for the improvement of social intelligence to promote students' academic achievement.

Keywords: Academic Achievement, Social Intelligence, Student. 


\section{بررسى ارتباط هوش اجتماعى با يِشرفت تحصيلى در دانشجويان هوشبرى و اتاق عمل

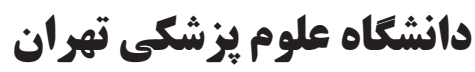

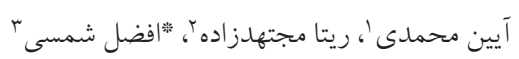

جكيده

مقدمه: يكى از ابعاد مههم در نظام آموزش عالى كشور، يیشرفت تحصيلى دانشجويان است. با شناسايى به موقع دانشجويان

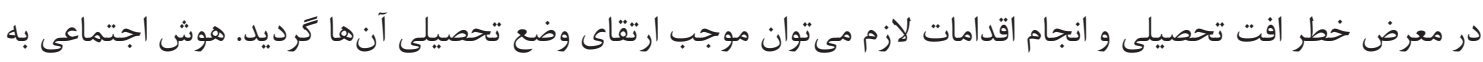

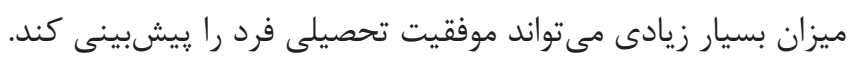

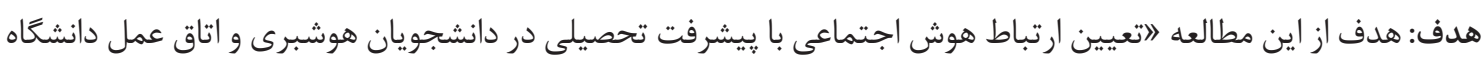
علوم يزشكى تهران" مى باشد.

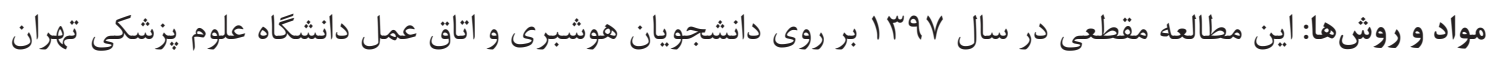

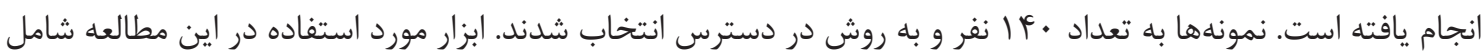
يرسشنامه دموكرافيك و يرسشنامه استاندارد هوش اجتماعى "ترومسو " Tromso Social Intelligence Scale) بود. جهت

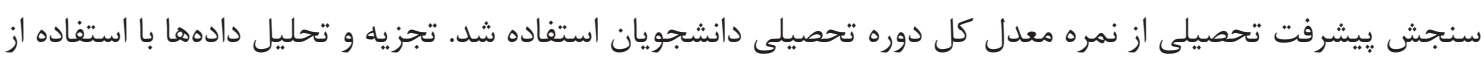

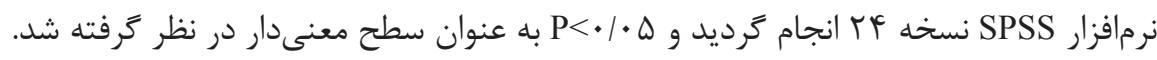

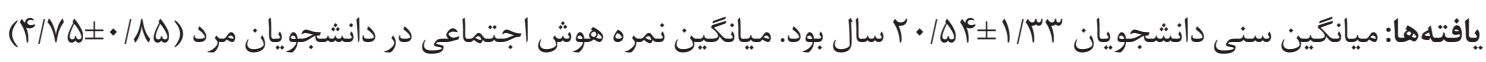

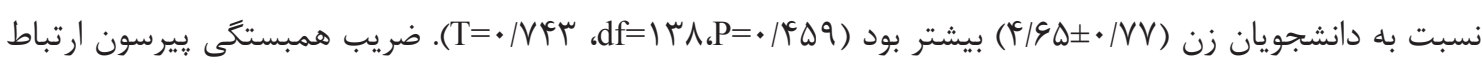

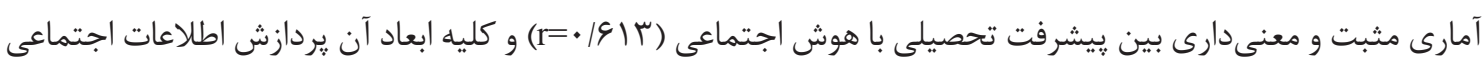

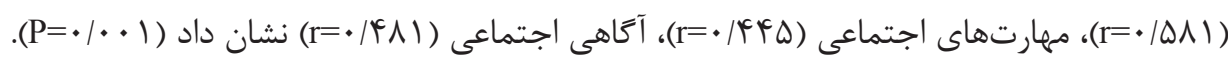

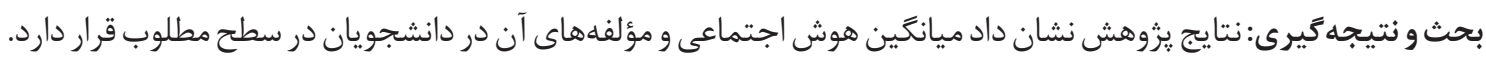

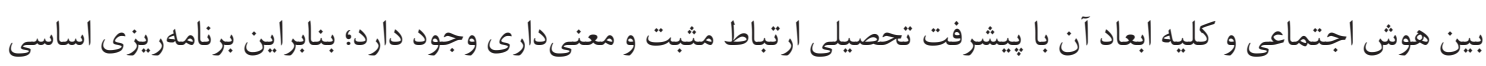

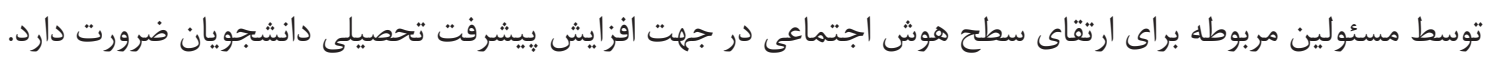
كلمات كليدى: بيشرفت تحصيلى، دانشجو، هوش اجتماعى.

وابسته، تحت تأثير يك عامل نيست، بلكه عوامل متعددى بر روى دانشجويان است و مىتوان از آن به عنوان شاخص عمده سنجش آنش تأثير را بر بيشرفت تحصيلى دارند (؟، ؟). سال هاى متمادى تصور كيفيت آموزش ياد كرد (1). ييشرفت تحصيلى، به عنوان متغير ان بهان 


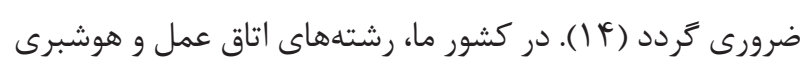

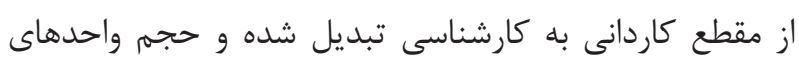

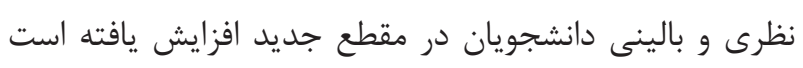

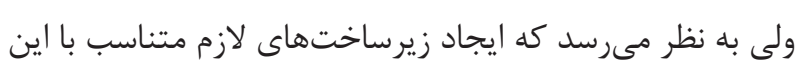

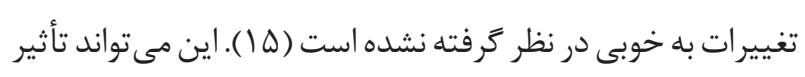
منفى زيادى در فرايند آموزشى و موفقيت تحصيلى دانشجويان

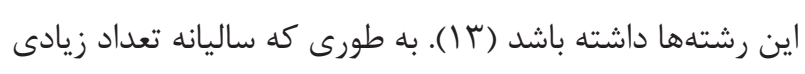

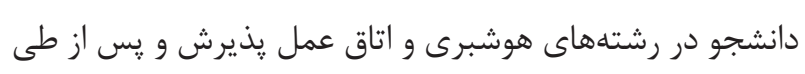

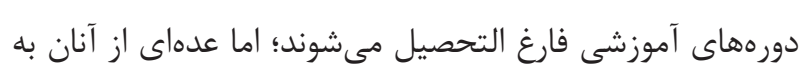

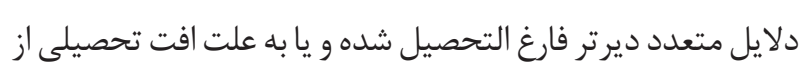

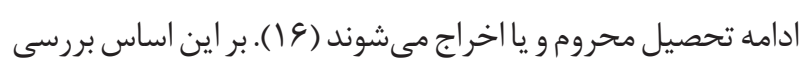

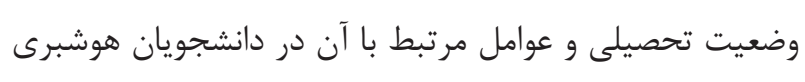

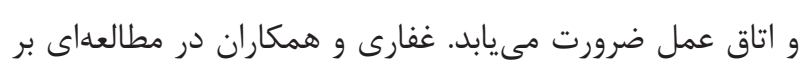

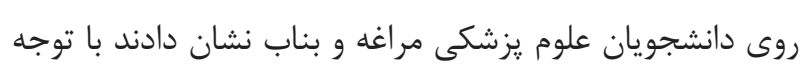

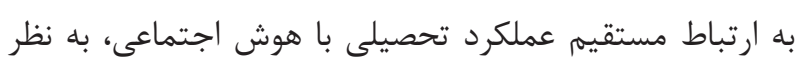
مىرسد هوش اجتماعى باعث افزايش عملكرد تحصيلى دانشجويان مىشود (9). رحيمى نيز در مطالعهاى، هوش اجتماعى دانشجويان

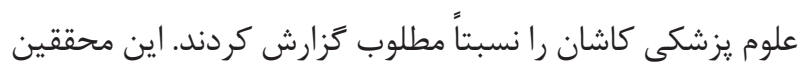

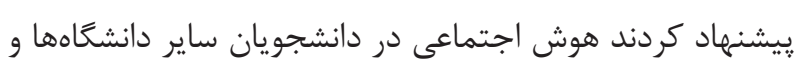

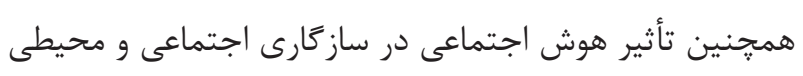
دانشجويان توسط ساير محققين بررسى شود (IV).

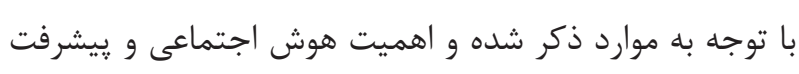
تحصيلى در دانشجويان رشته اتاق عمل و هوشبرى كه عهدهدار ارائه

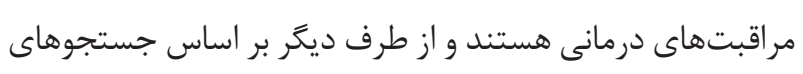

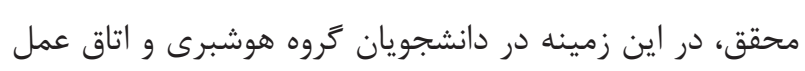

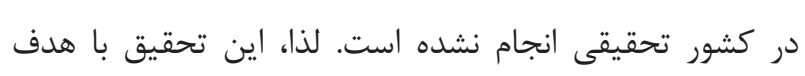

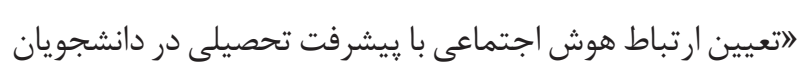
هوشبرى و اتاق عمل دانشاءه علوم يزشكى تهران \ا انجام شد.

\section{مواد و روشها}

يزوهش حاضر، يك مطالعه همبستخى از نوع مقطعى است كه

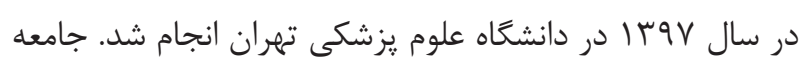
يزوهش را دانشجويان كارشناسى هوشبرى و اتاق عمل دانشكاه علوم يزشكى تهران تشكيل مى داد. حداقل حجم نمونه با استفاده
بر اين بود كه ضريب هوشى تنها شاخص ميزان موفقيت افراد است، اما روانشناسان دريافتند كه جنبههاى غيرشناختى مانند عوامل عاطفى و اجتماعى نيز داراى اهميت زيادى هستند (؟).

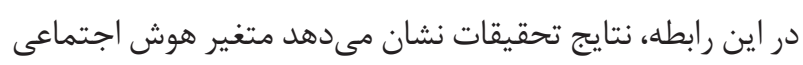
از قوىترين متغيرها براى ييشبينى عملكرد تحصيلى دانشجويان

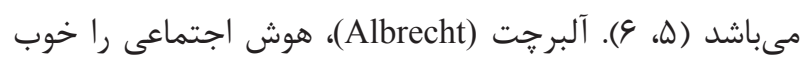

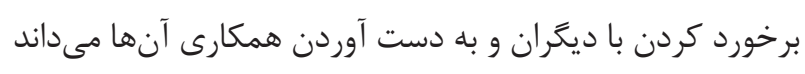

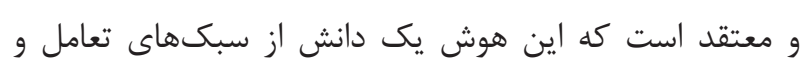

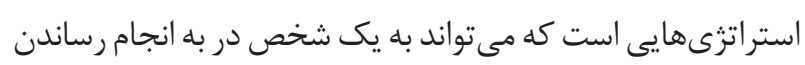
اهدافش در برخورد با ديخران كمك كند (V). كسب موفقيت تحصيلى در بين دانشجويان كروه علوم يزشكى به ديه

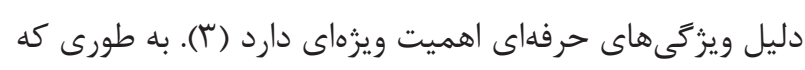

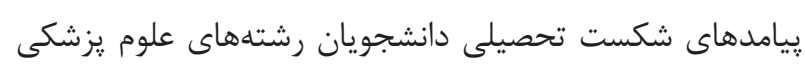

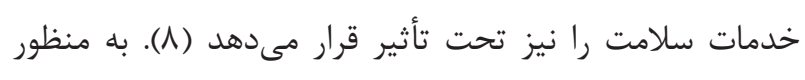

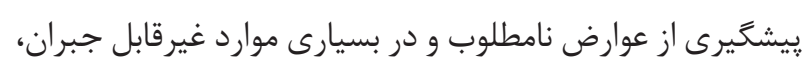

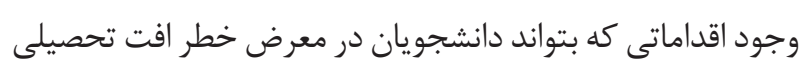

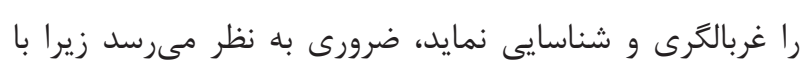
شناسايى به موقع دانشجويان در معرض خطر و همكارى درون

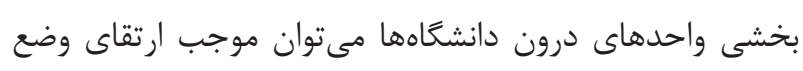

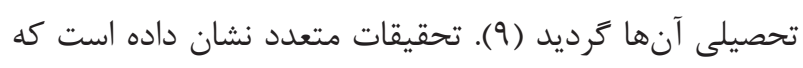

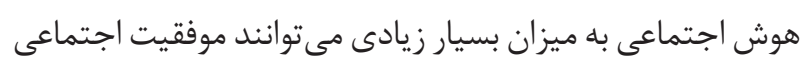

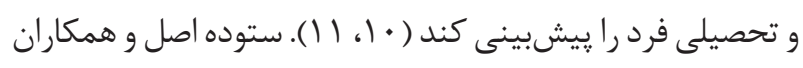

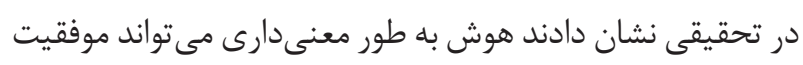

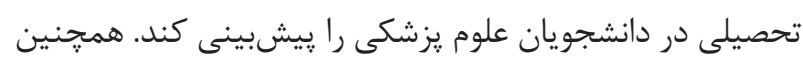

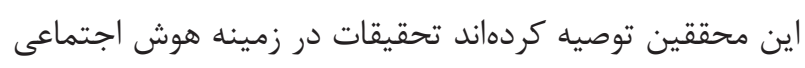

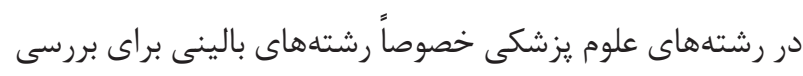
رابطه بين وضعيت اجتماعى با بيشرفت تحصيلى در اين دانشجويان

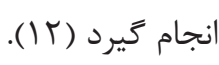

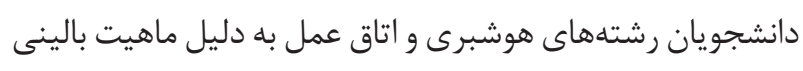

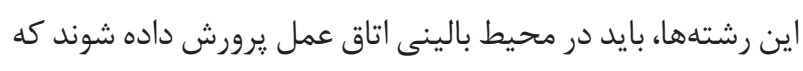

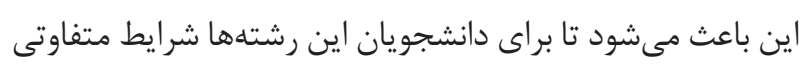

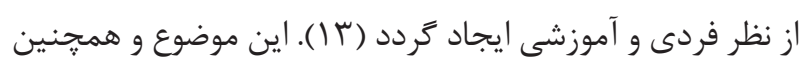

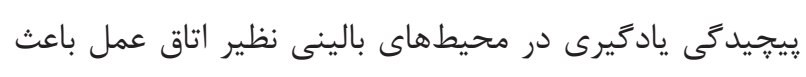

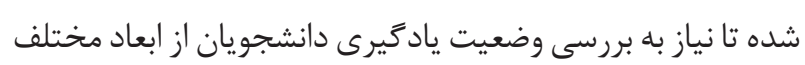


خودشان درباره هر سؤال يا ماده را بر روى يك مقياس V درجهاى

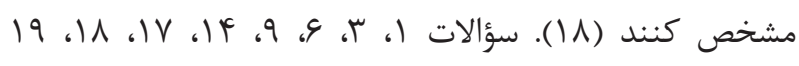

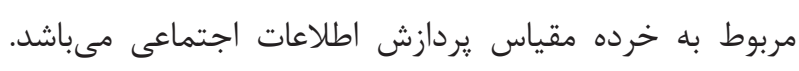

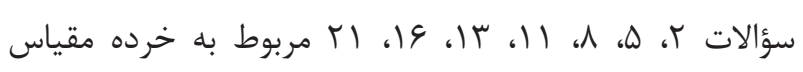

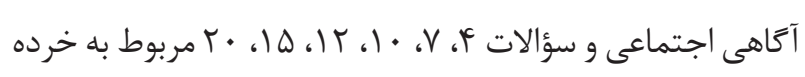
مقياس مهارتهاى اجتماعى مى باشند (9 (1). سيلورا (Silvera) و

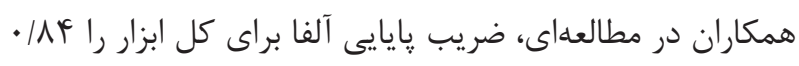

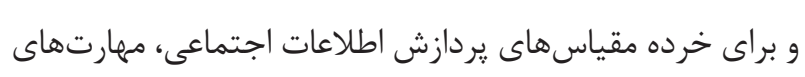

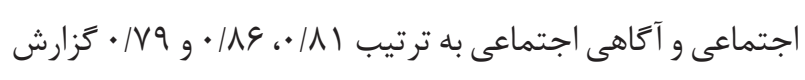

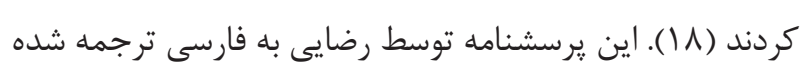

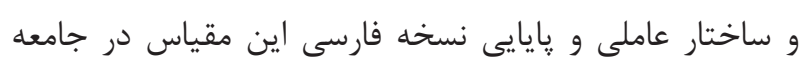

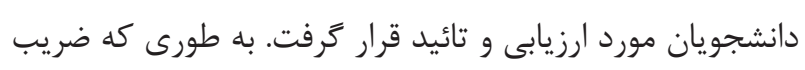

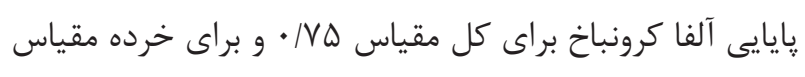

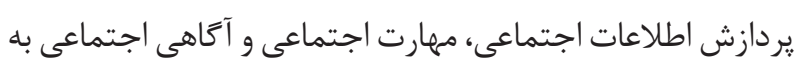

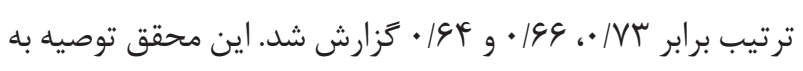
جدول 1 - مشخصات دموكر افيك واحدهاى مورد يثوهش

\begin{tabular}{|c|c|c|}
\hline تعداد (درصد) & وضعيت & متغير \\
\hline $\begin{array}{l}(r V / q) \Delta r \\
(\varepsilon Y / I) \wedge V\end{array}$ & زمرد & جنسيت \\
\hline$\left(Y G / T^{C}\right) \Psi V$ & دوم & \multirow{4}{*}{ ترم تحصيلى } \\
\hline מש(G/G) & جهارم & \\
\hline$(r+/ q) F q$ & ششم & \\
\hline$(I V / I) Y F$ & هشتم & \\
\hline $\begin{array}{l}(r V / q) \Delta r \\
(\varepsilon r / l) \wedge V\end{array}$ & خنزل شخاه شَصى & محل سكونت \\
\hline$(\Delta \cdot / V) \vee 1$ & آزاد & \multirow{3}{*}{ شغل یدر } \\
\hline$(Y) / F) F F$ & كارمند & \\
\hline$(I V / 9) r \Delta$ & بازنشسته & \\
\hline$(\Delta / \vee) \varphi$ & آزاد & \multirow{3}{*}{ شغل مادر } \\
\hline$(1 / / \Delta) r G$ & كارمند & \\
\hline$(V \Delta / V)) \cdot \varphi$ & خانهدار & \\
\hline$(V / I))$. & بىسواد & \multirow{3}{*}{ تحصيلات يدر } \\
\hline$(9 V / 1) q 4$ & زير ديِلم & \\
\hline (T山/V)rG & دانشعاهى & \\
\hline$(\Delta / \cdot) V$ & بى سواد & \multirow{3}{*}{ تحصيلات مادر } \\
\hline 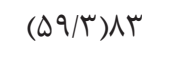 & زير ديڤلم & \\
\hline$(V T \Delta) \Delta \cdot$ & دانشخاهى & \\
\hline
\end{tabular}

از فرمول حجم نمونه بر اساس نتايج مطالعات مشابه (ه) باضريب

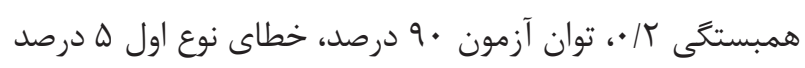
به تعداد سما نفر محاسبه گرديد. $n=\frac{\left(Z_{\dot{a}}+Z_{1-\hat{a}}\right)^{r}}{\frac{1}{r}\left[\log _{e}\left(\frac{1+r}{1-r}\right)\right]}+r=>$ $n=\frac{(1 / 9 \varphi+1 / 9 \varphi)^{r}}{\frac{1}{r}\left[\log _{\mathrm{e}}\left(\frac{1+\cdot / r}{1-\cdot / r}\right)\right]}+r=>$ $n=\frac{1 r / 99}{\cdot / 1}+r=1 r r$ با احتساب احتمال ريزش در نهايت • l ا نفر وارد مطالعه شدند.

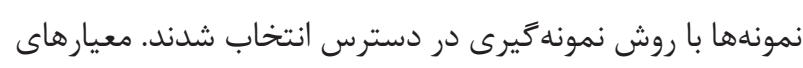

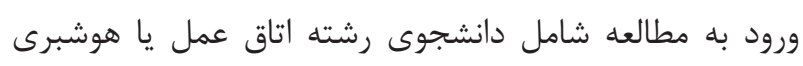

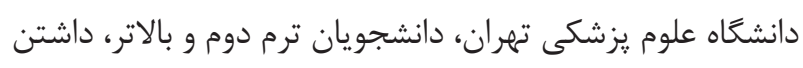

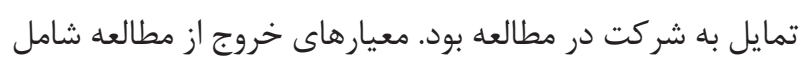

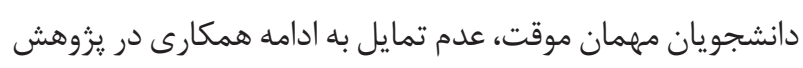

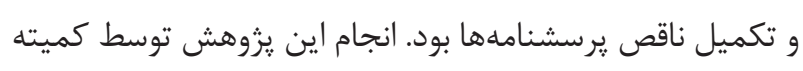

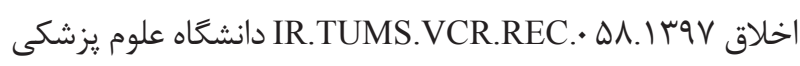

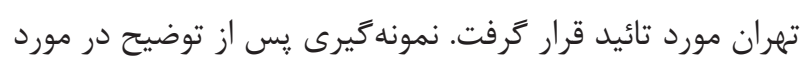

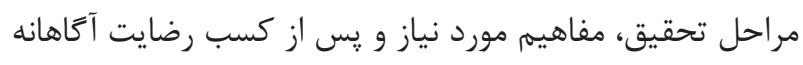

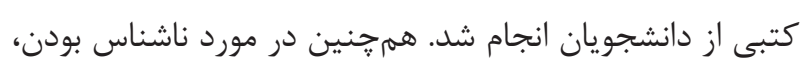

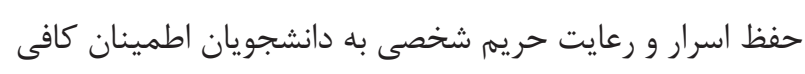

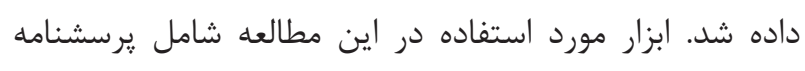

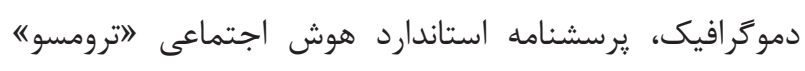
بود. يرسشنامه اطلاعات (Tromso Social Intelligence Scale) جمعيت شناختى يك فرم يزوهشخر ساخته بود كه شامل اطلاعات

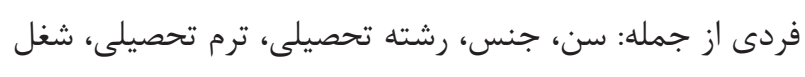
يدر، شغل مادر، تحصيلات يدر و تحصيلات مادر بود.

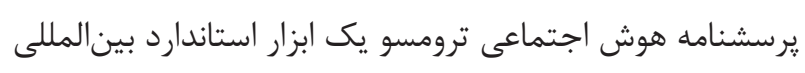

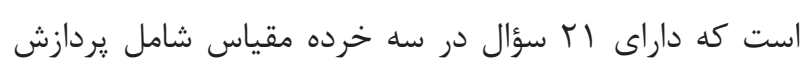

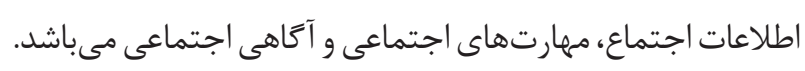

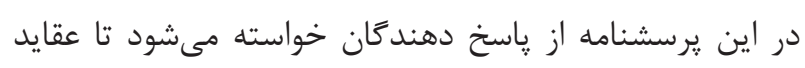




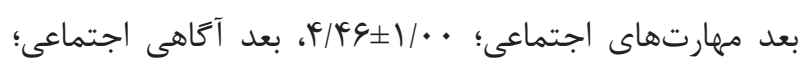

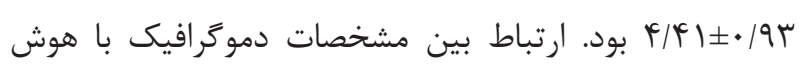

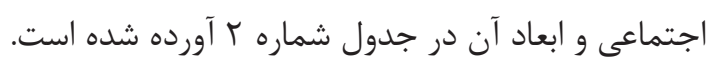

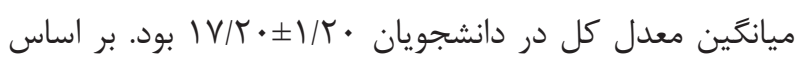
آزمون آمارى تى تست، ميانخين معدل كل درين در دان دانشجويان زن (IV///

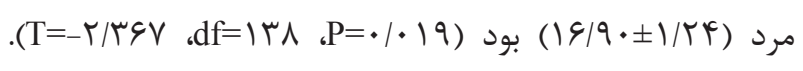

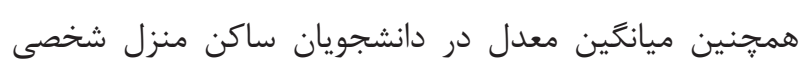
خ به طور معنى (IV/FTI//N)

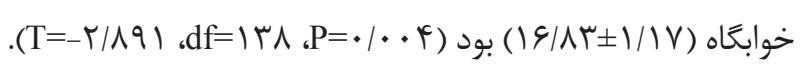
ضريب همبستكى ييرسون ارتباط آمارى مثبت و معنى دارى بين

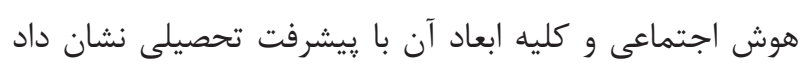

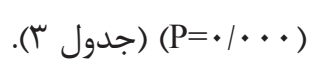

بحث و نتيجه كيرى اين يزوهش با هدف تعيين ارتباط بين هوش هيجانى با پيشرفت
استفاده از اين ابزار در جامعه دانشجويان نمودهاند (9 (1). جهت سنجش ييشرفت تحصيلى دانشجويان از نمره معدل كل

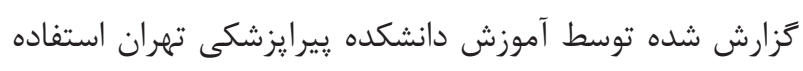
شد. در نهايت جهت تجزيه و تحليل دادههاى تحقيق از نرمافزار

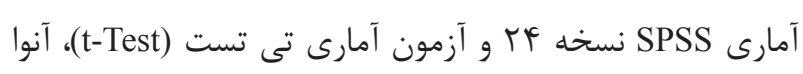
و ضريب همبستخى يِيرسون (Anova)

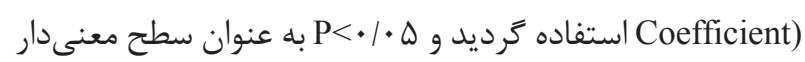
در نظر كرفته شد.

يافتهها

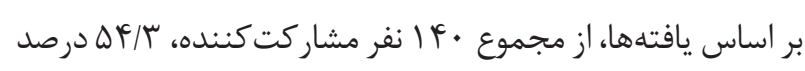

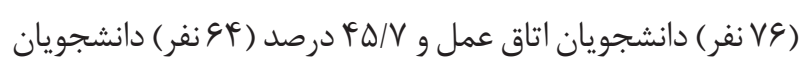

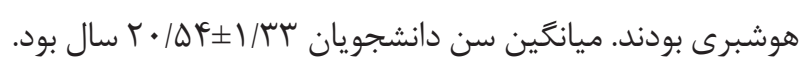
ساير مشخصات دموكرافيك در جدول شماره ا آورده شده است.

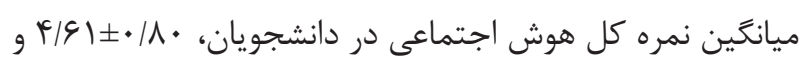
ميانكين نمره در بعد يردازش اطلاعات اجتماعى؛

جدول r - ميانغين و انحراف معيار هوش اجتماعى و ابعاد آن بر حسب مشخصات دموكر افيك

\begin{tabular}{|c|c|c|c|c|}
\hline \multicolumn{4}{|c|}{ ابعاد هوش اجتماعى } & \multirow{4}{*}{ متغير } \\
\hline نمره كل هوش اجتماعى & آكاهى اجتماعى & مهارت هاى اجتماعى & يردازش اطلاعات اجتماعى & \\
\hline ميانغين & ميانتين & ميانگين & ميانغين土 & \\
\hline انحراف معيار & انحراف معيار & انحراف معيار & انحراف معيار & \\
\hline$\varphi / \vee \Delta \pm \cdot / \wedge \Delta$ & $F / T Y \pm \cdot / 9 T$ & $F / V F \pm \cdot / 9 \Delta$ & $4 / \wedge 9 \pm 1 / 1)$ & 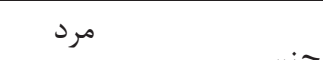 \\
\hline$F / 90 \pm \cdot / V V$ & $F / \Delta r \pm \cdot / q 1$ & $f /|c| \pm 1 / \cdot r$ & $\Delta / \cdot r \pm \cdot / q 1$ & جنس \\
\hline$" \mathrm{~T}=-\cdot / V \mathrm{~F}^{\mathrm{N}}$ & $* T=-1 / 9 F T$ & $\mathrm{~T}=-\cdot / \mathrm{VH}$ & $\mathrm{F}=-\cdot|V| F \mid$ & *نتايج آزمون تى تست \\
\hline $\mathrm{P}=\cdot / \mathcal{L} \Delta q$ & $\mathrm{P}=\cdot / \cdot \Delta \varphi$ & $\mathrm{P}=\cdot / 4 \varepsilon$ & $\mathrm{P}=\cdot / \uparrow \varphi$ & \\
\hline$F / V I \pm \cdot / V \Delta$ & $F / \Delta r \pm \cdot / \Lambda 9$ & $F / \Delta r \pm 1 / \cdots$ & $\Delta / \cdot 9 \pm \cdot / 9 \Delta$ & \multirow{2}{*}{ محل سكونت } \\
\hline$\uparrow / \uparrow \Delta \pm \cdot / \wedge \Delta$ & P/THE./QQ & $F / r F \pm 1 / \cdots$ & $F / V V \pm I / \cdot r$ & \\
\hline $\mathrm{T} T=-1 / 91 \mathrm{~V}$ & "T $=-I / V \wedge V$ & $\mathrm{~T}=-1 / \cdot \Delta \varphi$ & $\mathrm{T}=-1 / \lambda \vee \Lambda$ & \multirow[t]{2}{*}{ "نتايج آزمون تى تست } \\
\hline $\mathrm{P}=\cdot / \cdot \Delta \mathrm{V}$ & $\mathrm{P}=\cdot / \cdot \sqrt{ } q$ & $\mathrm{P}=\cdot / r q \mu$ & $\mathrm{P}=\cdot / \cdot q \mu$ & \\
\hline$F / F r \pm \cdot / 9 F$ & $\varphi / \mu \varepsilon \pm 1 / \cdots$ & $f / 1 \Delta \pm 1 / \cdot 9$ & $F / V \varepsilon \pm 1 / T$. & 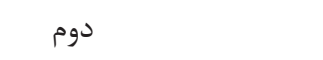 \\
\hline$Y / Q V \pm \cdot / V T$ & $F / 4| \pm \cdot| \wedge r$ & $F / V \cdot \pm \cdot / \Lambda q$ & $\uparrow / q \mu \pm \cdot / \Lambda \Lambda$ & جهارم \\
\hline$\uparrow / \varphi \wedge \pm \cdot \mid \wedge \varphi$ & $f / f y \pm 1 / \cdot V$ & $r / 4 q \pm 1 / 1 r$ & $\Delta / \cdot \wedge \pm 1 / \cdot 9$ & ششم \\
\hline$\varphi / q \cdot \pm \cdot / \Delta q$ & $r / F \Delta \pm \cdot / \Lambda T$ & $F / V \Delta \pm \cdot / V q$ & $\Delta / 11 \pm \cdot / G$. & هشتم \\
\hline$F=\cdot / 9 V r$ & $\mathrm{~F}=\cdot 1 \cdot 9$. & $* F=r / M r$ & $F=1 / T 1 Q$ & **:نتايج آزمون تى تست \\
\hline $\mathrm{P}=\cdot / \boldsymbol{c} \cdot V$ & $\mathrm{P}=\cdot / 911$ & $\mathrm{P}=\cdot / 1 \ldots$ & $\mathrm{P}=\cdot / \mu \cdot V$ & \\
\hline
\end{tabular}


جدول r - همبستغى بين هوش اجتماعى و ابعاد آن با ييشرفت تحصيلى در دانشجويان

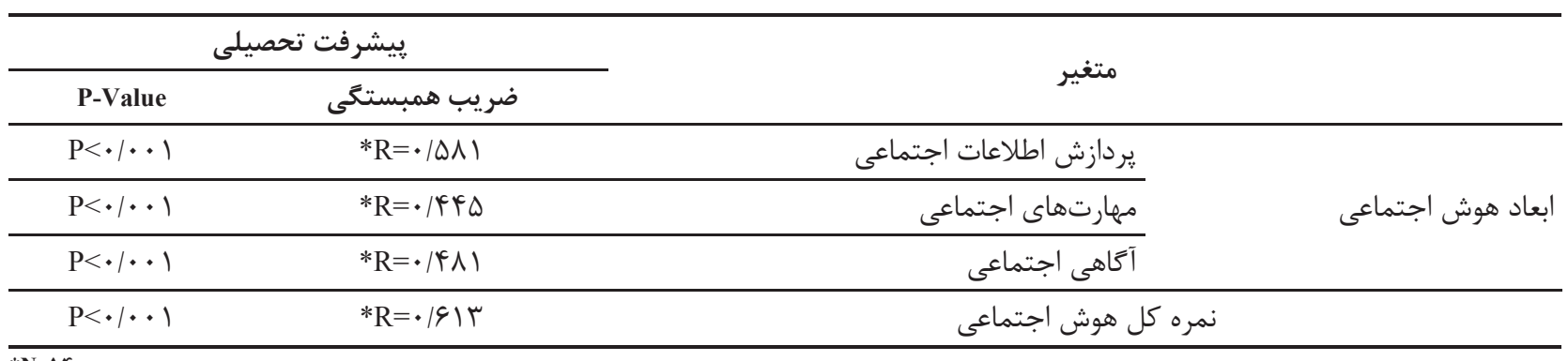

${ }^{*} \mathbf{N}=1 \%$.

ينهانى و نيز پيامهاى آشكار مىباشد (T) (Y). نصيرى و همكاران

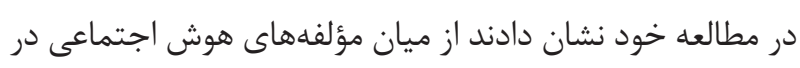

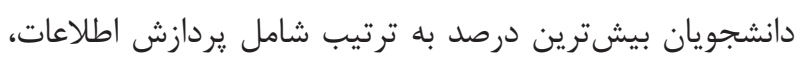

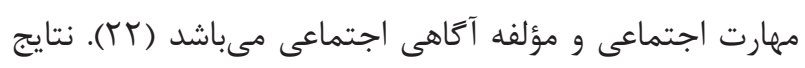

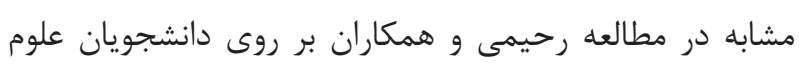

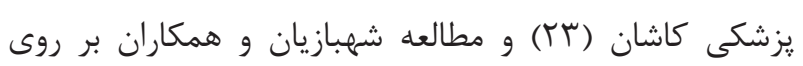

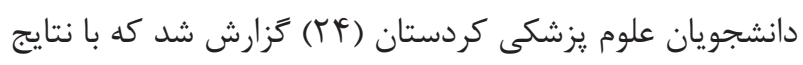

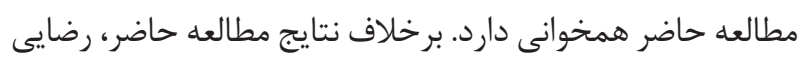

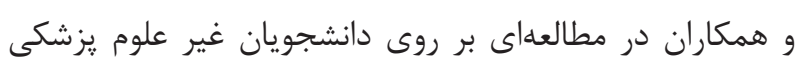

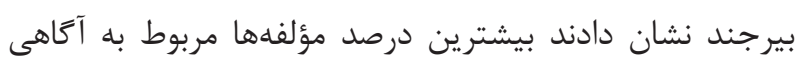

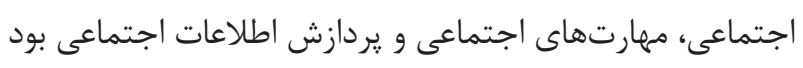

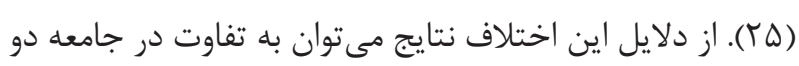

$$
\text { يزوهش اشاره نمود. }
$$

در مطالعه حاضر، نمره هوش اجتماعى و كليه ابعاد در دانشجويان

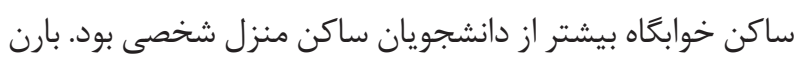

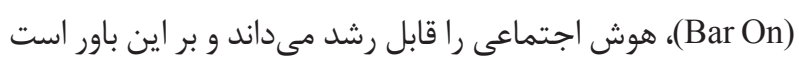

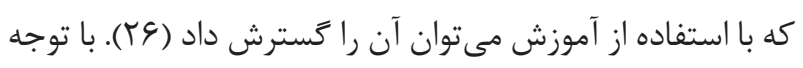

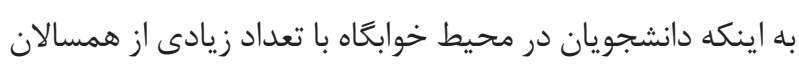

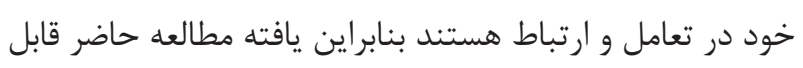
انتظار است. مهارتهاى اجتماعى به عنوان وسيله ارتباط ميان فرد و محيط تعريف مىشود و محققان معتقدند كه اين وسيله

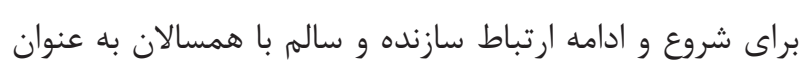

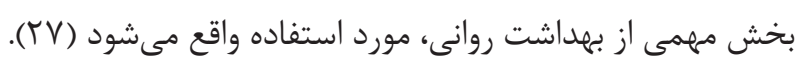

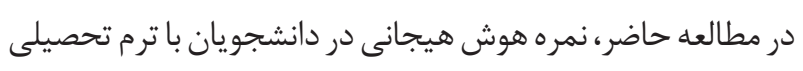

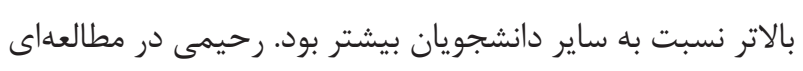

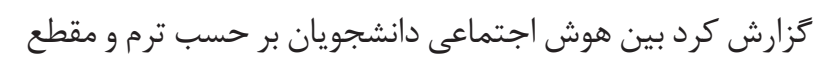

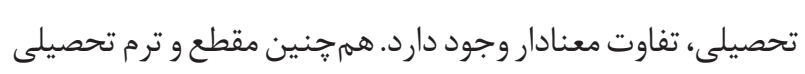

تحصيلى در دانشجويان هوشبرى و اتاق عمل دانشگاه علوم يزشكى

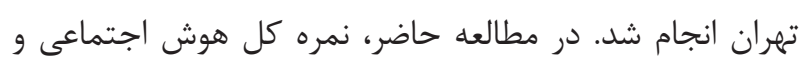

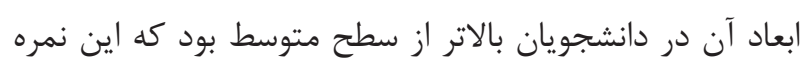

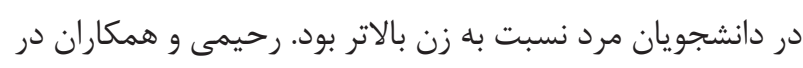

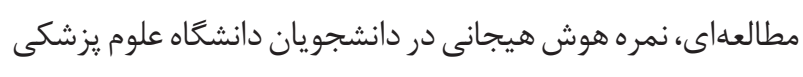

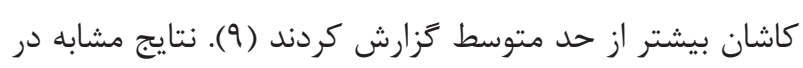

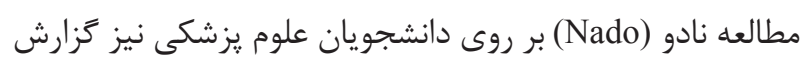

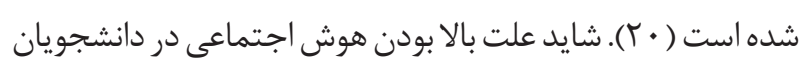
علوم يزشكى به خاطر ماهيت رشته باشد كه مستلزم تعامل و ارتباط

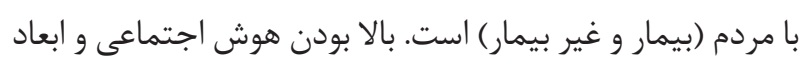
آن در دانشجويان هوشبرى و اتاق عمل اين مطالعه، نشان مىدهدي

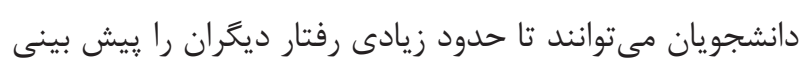

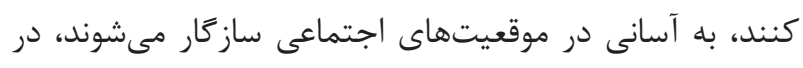
ارتباط با ديكران از كلماتى كه در شأن آنها است استفاده مئى كنند

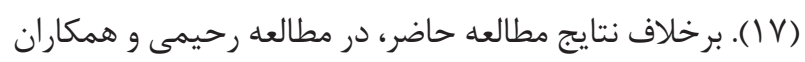

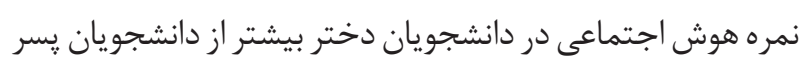

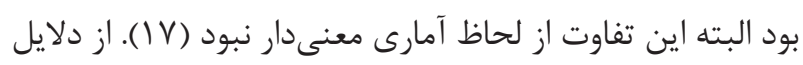
اين تناقض مىتوان به تفاوت در جامعه يزووهش، دانشعاه محل تحصيل و محل زندگى دانشجويان اشاره نمود. شايد علت بيشتر بودن هوش اجتماعى در دانشجويان يسر نسبت به دانشجويان

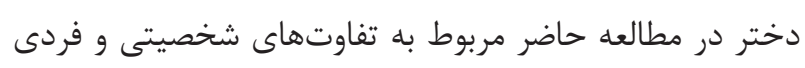

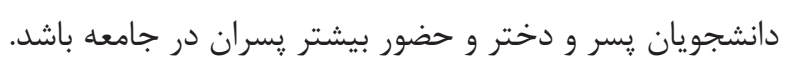

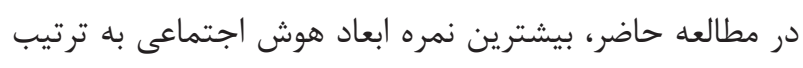

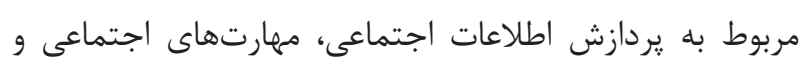

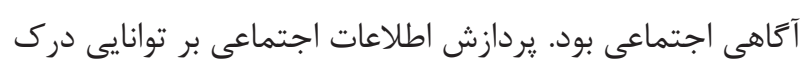

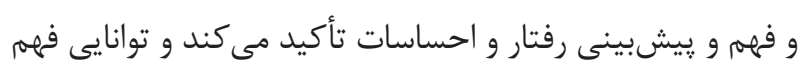

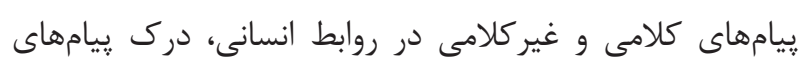


در خارج از منزل يدرى زندكى مى كنند ممكن است از حمايتهاى

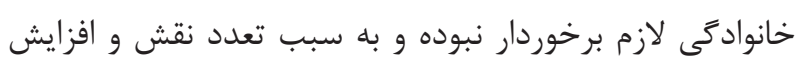

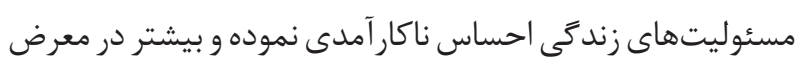

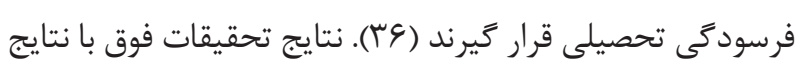

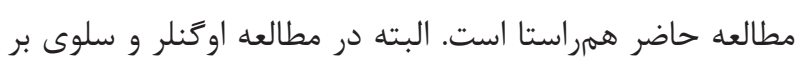

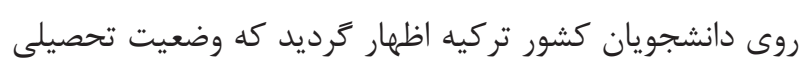
در دانشجويان ساكن خوابخاههاى دانشجويى وضعيت تحصيلى دونى بهترى دارند (r) كه با مطالعه فعلى در تناقض است. علت اين عدم توافق را مىتوان در شرايط متفاوت خوابكاههاى دانشجويى داريى و بافت فرهنگى دو كشور جستجو كرد.

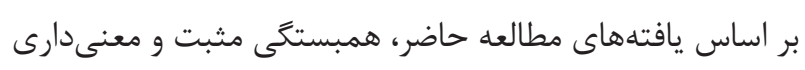

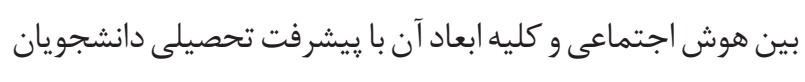
وجود داشت. هوش اجتماعى يك پيش بينى كننده موفقيت

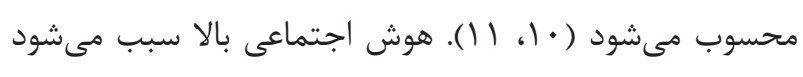
افراد در جذب دانش جديد به طور كلى موفق عمل كنند (YV).

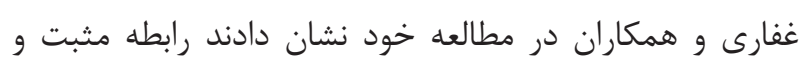

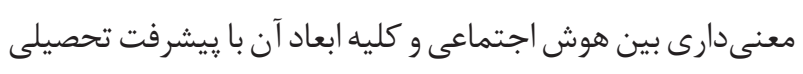

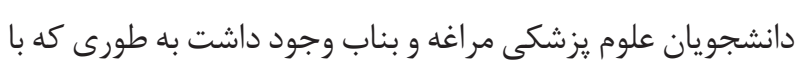

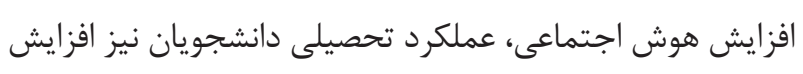

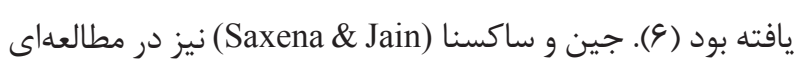
كزارش كردند كه عملكرد تحصيلى بالا به هوش اجتماعى وابسته

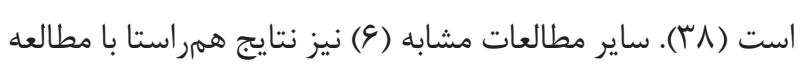

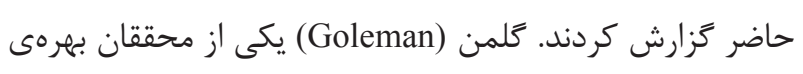

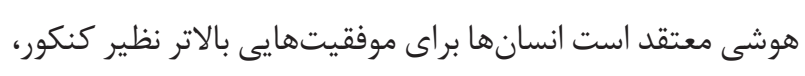
آزمونهاى استخدامى، تحصيل نياز به قدرتى بالاتر از هوشهاى مهاى

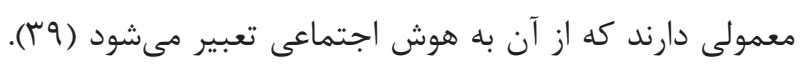

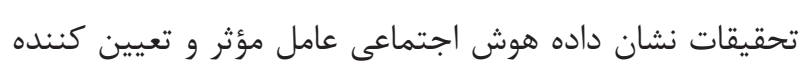
در برآيندهاى زندگى واقعى مانند موفقيت در دانشخاه، تحصيل، شغل و روابط بين شخصى مى باشد. هوش اجتماعى به دانشجويان كمك مى كند ارتباط بهترى با استادان، همكلاسى ها و ديخ ديخران

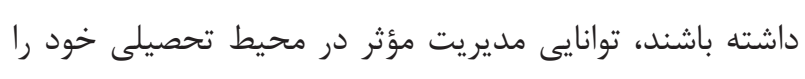

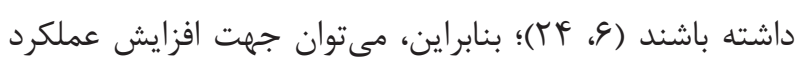
تحصيلى دانشجويان از روشهاى تقويت هوش اجتماعى استفاده نمود (9). از محدوديتهاى اين مطالعه، نمونه ديرى با استفاده
بر هوش اجتماعى دانشجويان، اثر كذار است كه اين شايد به خاطر

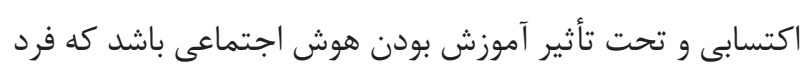

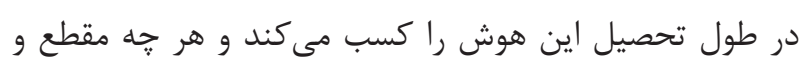

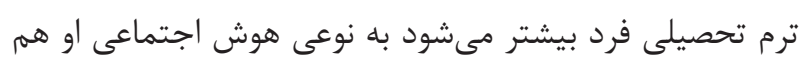

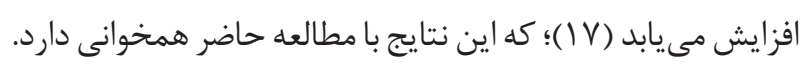

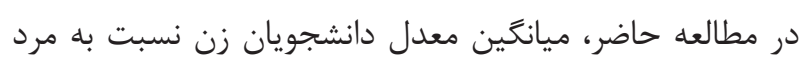

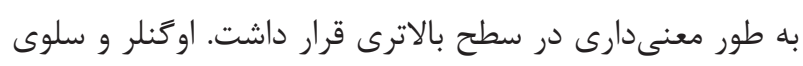

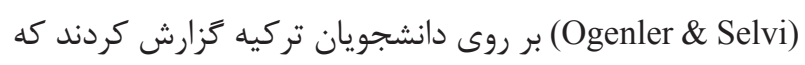

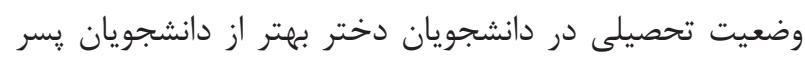

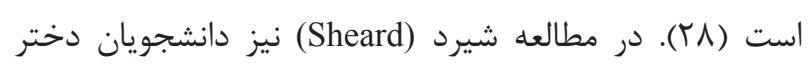

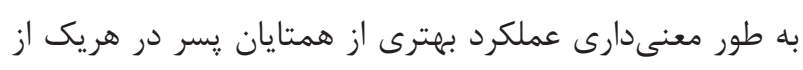

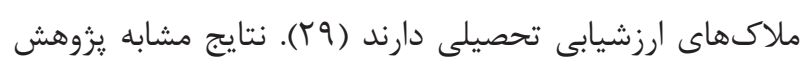

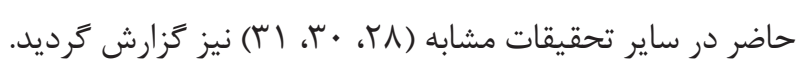

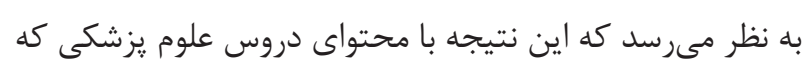
بيشتر ماهيت حفظى دارد مرتبط باشد. نتيجه تحقيقات نشان

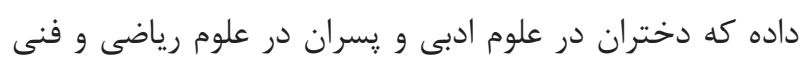

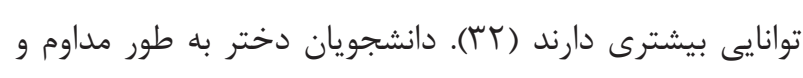

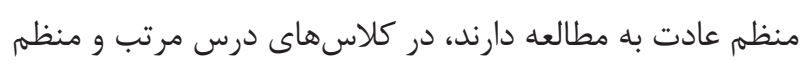

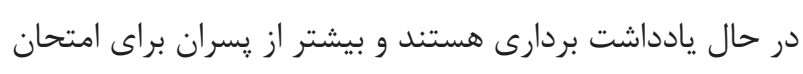

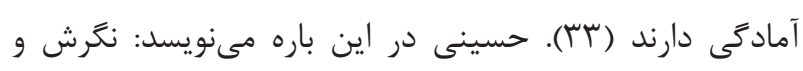

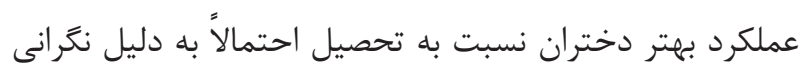

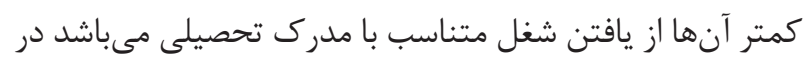

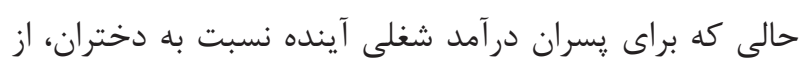

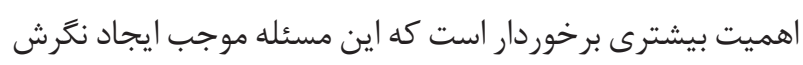

و عملكرد پايينترى نسبت به تحصيل شده است (YY).

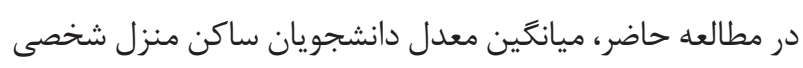

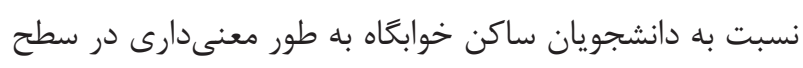

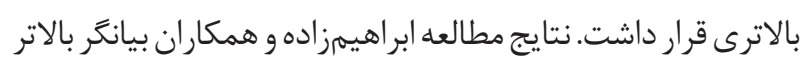

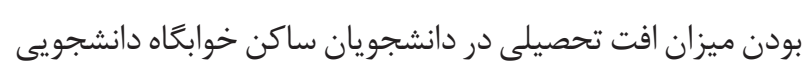

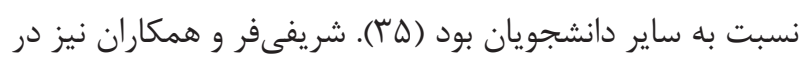
مطالعهاى نشان دادند سكونت خارج از منزل يدرى فرسودىى و و

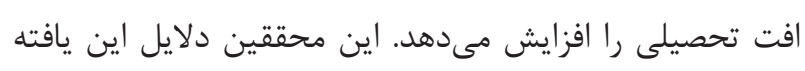

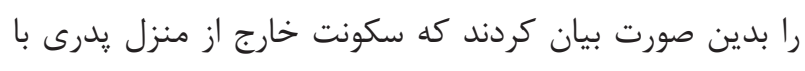

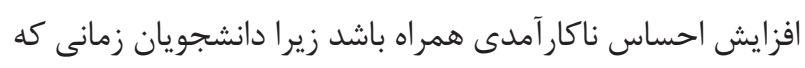


برَزارى كاركًاهها و سخنرانىهاى مناسب، مشاركت خانوادهها

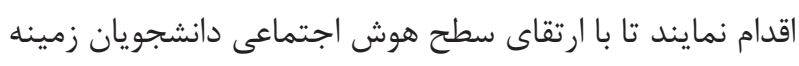

$$
\text { يمرفت تحصيلى آنها فراهم كردد. }
$$

\section{تشكر و قدردانى}

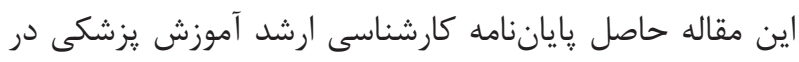

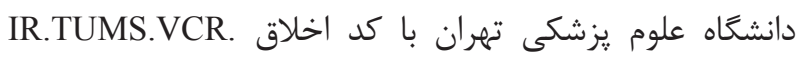

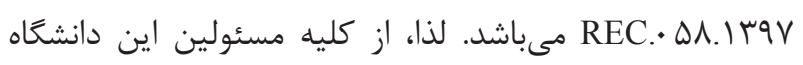

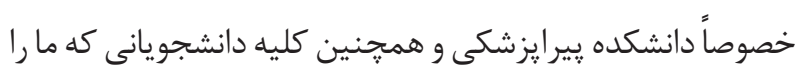
در انجام اين يزوهش يارى نمودند كمال تشكر و قدردانى را داريمه.

\section{تضاد منافع}

بدين وسيله نويسندگًان تصريح مىنمايند كه هيجزَنه تضاد منافعى در خصوص يزوهش حاضر وجود ندارد.

\section{References}

1- Davoodi S. Presenting the Prediction Model of Academic Achievement with Emphasizing the Mediate Role of Cognitive, Motivational and Behavioral Engagement. Research in teaching and learning. 2014;1(4):69-76.

2- Cole K. Developmental Psychology. Tehran: Publications Samt; 2007.

3- Kouchakzadeh Talami S, Namazi A, Alizadeh SH. The Correlation between Emotional Intelligence and Academic Achievement on Nursing and Midwifery Students. Iran Journal of Nursing. 2016;29(102):1-10. http://dx.doi.org/10.29252/ijn.29.102.1

4- Ciarrochi J, Deane FP, Anderson S. Emotional intelligence moderates the relationship between stress and mental health. Personality and Individual Differences. 2002;32(2):197-209. http://dx.doi.org/10.1016/s0191-8869(01)00012-5

5- Meijs N, Cillessen AH, Scholte RH, Segers E, Spijkerman R. Social intelligence and academic achievement as predictors of adolescent popularity. J Youth Adolesc. 2010;39(1):62-72. http:// dx.doi.org/10.1007/s10964-008-9373-9 www.ncbi.nlm.nih.gov/ pubmed/20091217

6- Jafari M, Ahmadzade F. Investigation of the association between the components of emotional intelligence and academic achievement in students. Razi J Med Sci. 2014;21(125):85-93.

7- Albrecht K. Social intelligence: The new science of success: John Wiley \& Sons; 2006.

8- SadeghiMovahed F, Molavi P, Samadzadeh M, Shahbazzadegan B, Yousefi K. The study of individual and environmental factors affecting achievement of ardabil medical students. JHC. 2013;15(3):38-47.
از روش در دسترس و مبتنى بر هدف به جاى تصادفى بود. از ديخر محدوديتها، اطلاعات اين مطالعه (هوش هيجانى) از طريق خودَزارشدهى دانشجويان به دست آمده لذا، ممكن است اطلاعات به دست آمده به صورت كاملاً واقعى نباشد. استفاده از معدل دانشجويان طبق زَارش آموزش دانشكده براى سنجش ييشرفت تحصيلى از نقاط قوت اين مطالعه مىباشد. در نهايت نتايج مطالعه حاضر نشان داد ميانخين اجتماعى و ابعاد آن (شامل يردازش اطلاعات اجتماعى، مهارتهاى اجتماعى و آتاهى اجتماعى) در دانشجويان هوشبرى و اتاق عمل از ميانخين فرضى، بيشتر و به نوعى مطلوب است. بين هوش اجتماعى و ابعاد آن با ييشرفت تحصيلى همبستخى مثبت و معنى دارى وجود دارد كه مىتواند منجر به ارتقاى سطح تحصيلى دانشجويان كردد؛ بنابراين توصيه مىشود دانشعاهها با برنامهريزى اساسى در جهت ارتقاى هوش هيجانى دانشجويان نظير جذب روانشناسان خبره،

9- Rahimi B, Jabbari N, Rahmatnejad L, Mohammadpour Y, Kazemi N. Evaluation of the Faactors Affecting Students Academic Failure in Urmia University of Medical Science in 1390. J Urmia Nurs Midwifery Fac. 2013;11(8):614-21.

10- Azizi Nejad B, Madadi Kokje Yaran F, Jenaabadi H. Relationship of Educational Function of Medical Universities' Faculties with their Social Intelligence. Educ Strategy Med Sci. 2014;7(5):323-7.

11- Tabatabaee Z, Ojinezhad A, Qutash A. The Relationship between Social Intelligence with Entrepreneurship Skills and Creativity among Technical High School Students in Shiraz. J Manage System. 2015;6(21):85-102.

12- Sotodehasl N, Ghorbani R, Semnani V, Karimi B. Is the emotional intelligence an indicator of academic achievement in students in Medical Sciences? Koomesh. 2016;17(3):725-32.

13- Heshmati H. Effective factors in clinical education quality from the viewpoints of operation room and anesthesiology students in Torbat Heydarieh University of Medical Sciences. Iranian J Med Educat. 2015;15:601-12.

14- Ip WY, Kit Chan DS. Hong Kong nursing students' perception of the clinical environment: a questionnaire survey. Int $\mathrm{J}$ Nurs Stud. 2005;42(6):665-72. http://dx.doi.org/10.1016/j. ijnurstu.2004.09.019 www.ncbi.nlm.nih.gov/pubmed/15978595

15- Ghorbanian N, Abdollahzadeh Mahlani F, Kazemi Haki B. Effective Factors on Clinical Education Quality Anesthesiology and Operating Room Students View. Educ Strategy Med Sci. 2014;6(4):235-9.

16- Avary H, Najafi Parizi GA, Kabir K, Sadati L, Kohan M, Rahimzadeh Kivi M. Factors A Effecting Students Academic 
Achievement in the Alborz Medical Sciences Faculty of Medicine in 2012-2013. Alborz University Medical Journal. 2015;4(3):1506. http://dx.doi.org/10.18869/acadpub.aums.4.3.150

17- Rahimi H, Eftekhar HS. A Study of Social Intelligence in Students at Kashan University of Medical Sciences During Year 2015. Journal of Nursing Education. 2016;5(3):41-6. http://dx.doi. org/10.21859/jne-05036

18- SilveraDH,Martinussen M,DahlTI. The Tromso Social Intelligence Scale, a self-report measure of social intelligence. Scand J Psychol. 2001;42(4):313-9. http://dx.doi.org/10.1111/1467-9450.00242 www.ncbi.nlm.nih.gov/pubmed/11547906

19- Rezaie A. The Tromsø Social Intelligence Scale: Factorial Structure and Reliability of the Persian Version of Scale in the Students Population. J Manage System. 2011;5(20):65-82.

20- Nado T. A study on social intelligence of college students. Int J Cur Res. 2012;4(1):231-2.

21- Ghanbari S, Soltanzadeh V. The role of mediating emotional intelligence in the relationship between research self-efficacy and the motivation for academic achievement. $\mathrm{J}$ Education Measurement \& Evaluation Studies. 2016;6(14):41-67.

22- Nasiri F, Gilani M, Eskandari A. Relationship between Social Intelligence and Civic-Academic Behavior with Educational Effectiveness of Boolee Sina University Graduate Students in Hamadan. New Approach in Educatl Manage. 2014;5(1):175-88.

23- Rahimi H, Madani A, Eftekhar H. The analysis of relationship between social intelligence with social capital and social consistency in students at University of Kashan. Social Psychology. 2017;12(44):59-72.

24- Shahbaziyan Khonig A, Hasani O, Soleymani S. The Survey of the Role of Moral and Social Intelligence in High-Risk Behaviors of Students of Kurdistan University of Medical Sciences in the 20162017 Academic Year. JRUMS. 2018;17(1):39-52.

25- Rezaii R, Selm-Aabadi M, Barati H, Tanha T. Prediction of the entrepreneurial personality traits of students based on the components of social intelligence. Leadership and Training Management. 2016;10(2):67-80.

26- Bar-On R. The Bar-On Model of Emotional-Social Intelligence (ESI). Psicothema. 2006;18(1):13-25.

27- Youssefi F, Kheir M. The study of reliability and validity of Matson's social skills scale and comparing the performance of high school girls and boys on this scale, Social Sciences and Human Sciences Journal of Shiraz University. 2002;18(2):147-58.

28- Ogenler O, Selvi H. Variables affecting medical faculty students' achievement: a mersin university sample. Iran Red Crescent Med
J. 2014;16(3):e14648. http://dx.doi.org/10.5812/ircmj.14648 www.ncbi.nlm.nih.gov/pubmed/24829774

29- Sheard M. Hardiness commitment, gender, and age differentiate university academic performance. Br J Educ Psychol. 2009;79(Pt 1):189-204. http://dx.doi.org/10.1348/000709908X304406 www. ncbi.nlm.nih.gov/pubmed/18466672

30- Ahanchian MR, lotfi Fatemi SN. The relationship between time management skills and academic achievement in anesthesiology and operating room students. Military Caring Sciences. 2015;2(2):96-103. http://dx.doi.org/10.18869/acadpub.mcs.2.2.96

31- Mills C, Heyworth J, Rosenwax L, Carr S, Rosenberg M. Factors associated with the academic success of first year health science students. Adv Health Sci Educ Theory Pract. 2009;14(2):205-17. http://dx.doi.org/10.1007/s10459-008-9103-9 www.ncbi.nlm.nih. gov/pubmed/18293093

32- Van Matre JC, Valentine JC, Cooper H. Effect of Students' AfterSchool Activities on Teachers' Academic Expectancies. Contemp Educ Psychol. 2000;25(2):167-83. http://dx.doi.org/10.1006/ ceps.1998.0999 www.ncbi.nlm.nih.gov/pubmed/10753545

33- Smith * SN, Miller RJ. Learning approaches: examination type, discipline of study, and gender. Educational Psychology. 2005;25(1):43-53. http://dx.doi.org/10.1080/0144341042000294 886

34- Hosseini Shahidi L, Atarodi A, Moghimian M. The survey of using learning strategies rate in students. Horizon Med Sci. 2005;11(1):53-60.

35- Ebrahimzadeh F, Ghorbani M, Nasseryan J, Mardani M. Incidence of academic failure and its underlying factors in Lorestan University of medical sciences. yafte 2016;17(4):14-24.

36- Sharififard F, Nourozi K, Hosseini M, Asayesh H, Nourozi M. Related factors with academic burnout in nursing and paramedics students of Qom University of Medical Sciences in 2014. JNE. 2014;3(3):59-68.

37- Tabatabai Z, Ojinezhad A, Kaltash A. The relationship between social intelligence and entrepreneurship skills and creativity of students in Shiraz conservatories, a new approach in educational management. 2015;6(1):85-101.

38- Saxena DS. Social Intelligence of Undergraduate Students In Relation To Their Gender and Subject Stream. IOSR Journal of Research \& Method in Education (IOSRJRME). 2013;1(1):1-4. http://dx.doi.org/10.9790/7388-0110104

39- Goleman D. Emotional intelligence. New York: Bantam Books; 2005 . 